\title{
Does pain in individuals with multiple sclerosis affect employment? A systematic review and meta-analysis
}

\author{
Shahnaz Shahrbanian $\mathrm{MSc}^{1}$, Mohammad Auais $\mathrm{PhD}^{1}$, Pierre Duquette MD PhD², \\ Katie Anderson $\mathrm{BSc}^{3}$, Nancy E Mayo $\mathrm{PhD}^{1,3}$
}

\begin{abstract}
S Shahrbanian, M Auais, P Duquette, K Anderson, NE Mayo. Does pain in individuals with multiple sclerosis affect employment? A systematic review and meta-analysis. Pain Res Manag 2013;18(5):e94-e100.
\end{abstract}

BACKGROUND: Individuals with multiple sclerosis (MS) experience some of the highest unemployment rates among all groups of chronic illnesses. Pain has been found to be a common reason for sick leave or early retirement in healthy populations or other groups with chronic illness; however, there is little awareness regarding the effect of pain on the work status of individuals with MS.

OBJECTIVES: To estimate the extent to which individuals with pain differ in employment status compared with those without pain among MS patients.

METHODS: An extensive systematic review of the scientific literature was performed within the framework of the Cochrane Collaboration to identify studies focusing on the effect of pain on employment in individuals with MS. The following databases were searched: PubMed, EMBASE, PsychInfo, Web of Science, MD Consult and Elsevier, and Science Direct. The methodological quality of studies was assessed using the McMaster Critical Review Form.

RESULTS: Ten articles met the inclusion criteria and were included in the systematic review. Of these studies, five that exhibited clinical, methodological and statistical homogeneity were included in the meta-analysis. The between-groups (pain + versus pain -) pooled random OR of being employed was 0.7 (strong), and was significantly different from unity (95\% CI 0.5 to $0.9 ; \mathrm{P}=0.001$ ).

CONCLUSIONS: The results of the present study indicated that individuals with MS who experience pain were significantly more likely to report a decreased employment rate than individuals with MS who were pain free.

Key Words: Employment; Multiple sclerosis; Pain; Productivity; Review; Work

ultiple sclerosis (MS) is recognized as the most common neuroI logical cause of disability among young adults in North America (1-3). MS occurs in individuals during peak years of normal productivity, significantly impacting their ability to remain in the work force (1). Individuals with MS often have difficulty continuing to work due to the disability, different symptoms, mobility difficulties and other aspects of the disease $(1,3)$. Unemployment is defined by the International Labor Organization as being without a paying job for four weeks or longer (4). The overall rate of unemployment in the MS population varies from $22 \%$ to $80 \%(5-7)$. This variation may be due to differences in patients, disease and work-related characteristics as well as the definition of employment used (8). It has been found that at the time of diagnosis, $60 \%$ of individuals with MS are in full-time employment; however, after five years, $70 \%$ to $80 \%$ of patients become unemployed (9-12).

The total indirect cost of MS for Canadians was reported to be \$313.7 million in 1994 (13). Indirect costs include lost productivity,

\section{La douleur nuit-elle à l'emploi chez les personnes atteintes de sclérose en plaques? Une analyse systématique et une méta-analyse}

HISTORIQUE : Les personnes atteintes de sclérose en plaques (SP) présentent l'un des taux de chômage les plus élevés de tous les groupes de maladie chronique. Il est établi que la douleur est une raison courante de prendre un congé de maladie ou une retraite anticipée dans les populations en santé ou d'autres groupes ayant une maladie chronique. Cependant, on ne sait pas grand-chose de l'effet de la douleur sur le statut d'emploi des personnes atteintes de SP.

OBJECTIFS : Évaluer dans quelle mesure le statut d'emploi des personnes atteintes de SP qui sont victimes de douleurs diffère de celui des personnes atteintes de SP qui n'en sont pas victimes.

MÉTHODOLOGIE : Les chercheurs ont effectué une vaste analyse systématique des publications scientifiques dans le cadre de la Collaboration Cochrane afin d'extraire les études portant sur l'effet de la douleur sur l'emploi des personnes atteintes de SP. Ils ont fouillé les bases de données suivantes : PubMed, EMBASE, PsychInfo, Web of Science, MD Consult et Elsevier, ainsi que Science Direct. Ils ont évalué la qualité méthodologique des études au moyen du formulaire d'examen critique McMaster.

RÉSULTATS : Dix articles respectaient les critères d'inclusion et ont été inclus dans l'analyse systématique. De ce nombre, les cinq qui présentaient une homogénéité clinique, méthodologique et statistique ont fait partie de la méta-analyse. Le risque rapproché aléatoire regroupé des intergroupes (douleur + par rapport à douleur -) à avoir un emploi s'élevait à 0,7 (fort), ce qui différait de manière significative de l'unité (95\% IC 0,5 à 0,9; $\mathrm{P}=0,001)$.

CONCLUSIONS : Selon les résultats de la présente étude, les personnes atteintes de SP victimes de douleurs étaient significativement plus susceptibles de déclarer un taux d'emploi moins élevé que celles qui n'en étaient pas victimes.

early retirement, sick leave, reduced hours of work and changing the type of work, whereas the direct costs of a disease relate to diagnosis and treatment (14). In a recent study, the mean total cost per MS patient per year was estimated to be $\$ 37,672$, of which $32 \%$ was attributable to patients' sick leave and retirement due to MS (15). These results confirm that indirect costs are major contributors to total costs in MS population.

Previous research has demonstrated that unemployed individuals generally report more depression, anxiety and social isolation than employed individuals (16). Research has also shown that being employed helps individuals with MS focus on their work activity rather than on their disease and its related symptoms and disability (17). Moreover, while work contributes to adult identity, financial security, life satisfaction and quality of life (QOL), the loss of ability to work is associated with decreased QOL due to the fear of decreased income and increased distress $(18,19)$. Thus, considering the importance of being employed, a clear understanding of the employment

${ }^{1}$ School of Physical $\mathcal{B}$ Occupational Therapy, Faculty of Medicine, McGill University; ${ }^{2}$ Notre-Dame Hospital (CHUM), University of Montreal;

${ }^{3}$ Division of Clinical Epidemiology, McGill University Health Centre, Royal Victoria Hospital, Montreal, Quebec

Correspondence: Shahnaz Shahrbanian, McGill University, School of Physical and Occupational Therapy, McGill University Health Centre/Royal

Victoria Hospital, Ross Pavilion R4.27, 687 Pine Avenue West, Montreal, Quebec H3A 1A1. Telephone 514-735-3105, fax 514-843-1493,

e-mail shahnaz.shahrbanian@mail.mcgill.ca 
barriers faced by individuals with MS will aid in the identification of appropriate interventions for removing barriers to employment.

There are many factors associated with unemployment in the MS population. Sociodemographic variables associated with unemployment include older age and lower level of education $(1,19,20)$. In addition, the results of previous studies have revealed conflicting results regarding sex difference in the percentage of patients who are still working (21-23). Disease-related factors associated with unemployment include longer disease duration and having relapsing-remitting MS (24-26). The impact of MS on employment also varies significantly depending on the nature of the occupation itself. For example, physically demanding jobs are more affected by symptoms such as fatigue, while jobs that require thinking are more affected by cognitive impairments (27).

In many studies, however, individuals with MS attribute their unemployment primarily to the symptoms they are experiencing. For example, one-half of unemployed individuals with MS reported physical disability as the reason for leaving their jobs (28), and individuals with higher Expanded Disability Status Scale scores are more likely to be unemployed $(22,26)$. Fatigue $(29,30)$, cognitive difficulties $(21,31)$ and depression $(17,32)$ have also been found to influence employment.

Pain is a prevalent symptom among individuals with MS $(5,33,34)$. Individuals with MS and pain report more depressive symptoms (35), greater diminished physical function (36), poorer mental and general health (37), and poorer health-related QOL (38) than individuals with MS who do not report pain. In addition, pain has been found to be a common reason for sick leave or early retirement in healthy populations or in other groups with chronic illness; however, there is little awareness of the role of pain in the work status of individuals with MS. The focus in MS is mostly on therapies to alter the disease course, and secondary health problems take a back seat to primary neurological deficits. Given the relative role of pain on decreased QOL and increased potential for psychological distress, and the social isolation of the MS population, it is important to understand the association between pain and work status. Therefore, the aim of the present review was to estimate, among individuals with MS, the extent to which individuals with pain differ in employment status compared with individuals without pain.

\section{Search strategy \\ Initially, the Cochrane Library and the Database of Abstracts of Reviews of Effectiveness were searched to determine whether a systematic review on this topic had been completed, and none was found. Subsequently, an extensive review of the scientific literature was performed by two of the investigators (SS, MA). The search period covered the years from inception to March 2012 in the following databases: PubMed/MEDLINE, EMBASE, PsychInfo, Web of Science, MD consult and Elsevier, and Science Direct. These electronic databases were searched using the fol- lowing key terms: multiple sclerosis, transverse mellitus, pain, discom- fort, job, work and employment. Searches were undertaken using MeSH headings and text words as suitable; no language restriction was applied. To identify other pertinent articles, the reference lists contained in all retrieved articles were searched.}

\section{Study selection}

Two reviewers (SS and MA) read all potentially relevant abstracts to identify publications that appeared to be eligible for the present review. From the chosen abstracts, the full texts were read, and studies were selected for the review based on the following inclusion or exclusion criteria:

- Type of publication: Only full publications in peer-reviewed journals were considered. Unpublished data and abstracts were not sought.

- Study design: All types of studies were included (randomized controlled trails, cross-sectional studies, pre/post studies, casecontrol studies, cohorts and case studies).
- Study population: Studies were included if the participants were older than 18 years of age and were diagnosed with possible, probable or definite MS. If the study population was a mixture of MS and other underlying diseases, the MS population had to represent the majority of the total study population, or results for MS had to be reported separately.

- Pain (exposure): Study participants had to experience any type of pain as an unpleasant sensory and emotional experience arising from their MS.

- Employment (outcome): The study had to include information on employment rate and status among MS patients who experienced pain. Individuals were considered to be employed if they were regularly scheduled to work several hours per week and were paid at the time of evaluation. Patients not participating in paid work were defined as not employed.

All discrepancies between the two reviewers were discussed and if a consensus was not reached, a coauthor (NM) was approached to decide.

\section{Data extraction}

To facilitate the comparison of findings across studies, the following information was extracted from each study: researcher(s) name(s) and date of publication, study design and quality assessment of the study, participants' characteristics (eg, sample size, age and sex), measures (pain and work-related variables and their related measures) and results, such as mean, SD and CIs, if data were provided.

\section{Quality assessment of studies}

The quality of all retrieved articles was evaluated using the Critical Review Form for Quantitative Studies developed by the McMaster University Occupational Therapy Evidence-Based Practice Research Group (39). Two reviewers (SS and MA) independently assessed the methodological quality of all relevant studies. Disagreements were resolved by consensus. Crude agreement and Cohen's Kappa coefficient was used to assess the inter-rater agreement between the two reviewers at the major steps of the review from study selection to quality assessment (40).

In addition, because research has shown that quality evaluation with numerical scores are arbitrary, inaccurate and unreliable (41), methodological quality of each criterion was reported as met, partially met or not met. Moreover, considering that employment rate was the outcome of interest, and that in all included studies employment was not the main outcome but rather a sociodemographic variable, the criteria for the quality assessment was modified wherever data were gathered without a reliable and valid measurement tool. Therefore, if the data regarding employment rate in both pain and pain-free groups were provided, the reviewers considered it to be met.

\section{Quantitative synthesis of studies (meta-analysis)}

In an effort to obtain a quantitative statistical summary showing the extent to which pain affects employment status, the results of comparable study findings were combined using a meta-analysis. Included studies may represent clinical and methodological diversity (eg, inconsistency in clinical settings, exposures and research questions). This inconsistency is called heterogeneity, which is defined as the variability among studies included in the meta-analysis (42). Statistical heterogeneity was tested using the $Q$ test $\left(\chi^{2}\right)$ and reported as the $\mathrm{I}^{2}$ statistic. A significant $Q$ test indicates only the presence of heterogeneity among the data included, whereas the $\mathrm{I}^{2}$ quantifies the magnitude of the heterogeneity (43). $\mathrm{I}^{2}$ ranges between $0 \%$ and $100 \%$, with higher values indicating greater heterogeneity (43). To adjust for heterogeneity when combining studies, researchers chose a random-effects model to determine whether results were robust; because this model is more conservative, especially for small samples, it helps to generalize the results to the general population, and assumes that these studies are a sample from all possible similar studies $(42,44)$. Data from comparable studies were then compared using a forest plot of the relative OR and $95 \% \mathrm{CI}$ between individuals with MS with and without pain (45). 
Publication bias was checked using both funnel plots and quantitative methods (classic fail-safe $\mathrm{n}$ test, Begg and Mazumdar rank correlation test, Egger's test of the intercept, and the trim and fill test) (46). Because each of these methods has limitations, several methods were used together $(47,48)$. The classic fail-safe $\mathrm{n}$ test calculates the number of 'null' studies that would need to be included for the combined P to exceed the significance level (0.05). The rank-correlation test (Kendall's tau-b), as suggested by Begg and Mazumdar (46), tests the significance of the inverse correlation between study size and effect size. A significant Begg correlation and Egger's test would suggest that bias exists. Finally, the trim and fill method was used, which essentially determines where the missing studies (if any) are likely to fall, adds them to the analysis, and then recomputes the combined effect $(47,48)$.

Evidence classification for the present study came from the Canadian Medical Association Journal because it covers all types of study designs (39). This rating system consists of four levels of evidence based on the design and quality of the included studies. Comprehensive Meta-Analysis version 2.0 (Biostat, USA) was used for statistical analysis.

\section{Number of articles sourced}

\section{RESULTS}

A tabular display of the study selection process is presented in Figure 1. A total of 175 abstracts were identified through different databases. After removal of 112 articles that were sourced from more than one database, 63 articles were screened for titles and abstracts. Of these, 29 abstracts were excluded. The primary reasons for exclusion were irrelevant, unpublished data; mixed study population for which data for MS were not presented separately; or MS was not the main population of interest. The remaining articles were then assessed for eligibility to determine whether they met inclusion criteria. Twenty-five studies did not meet inclusion on full review. The reference lists of the retrieved studies later revealed one additional article. Finally, 10 articles met the inclusion criteria and were included in the systematic review. Five of the studies that exhibited clinical, methodological and statistical homogeneity were included in the meta-analysis (Figure 2). A short description of each included study is presented in Table 1.

\section{Descriptive results}

Pain prevalence varied from $44 \%$ to $82 \%$. The variability in the percentage of pain in MS may be due to differences across the studies related to the patient sources, method of sampling, research methods for collecting the data and the focus on different dimension of pain (eg, frequency, intensity, and duration). Disease subtypes and severity of symptoms also varied across studies. Pain prevalence, severity and location were the most commonly used pain-related outcomes. The time frame for pain-related variables varied from one month to six months. The Numerical Rating Scale and bodily pain subscale of the Short Form-36 Health Survey were the most common measures used to assess pain across studies.

Rate of employment ranged from $28 \%$ to $57 \%$. Aside from the employment rate and status, other work-related outcomes included number of days off work, ability to work outside and inside home, type of occupation and hours of paid employment per week. The main cause of employment loss was unknown from these studies.

Forty-seven per cent to $66 \%$ of MS subjects with pain reported that pain interfered with their work. The effects of MS pain on employment results varied. Some of the studies found that individuals with pain reported that pain reduced their ability to work, while other studies could not find a significant difference; however, they mostly indicated an increasing proportion of patients not being employed in the presence of pain.

MS severity and disease subtypes and duration were the most common disease-related outcomes across studies. The study populations were recruited from community-dwelling populations, regional referral clinics, neurology treatment centres, newspapers, the Internet, neurologists' offices and the North American Research Committee

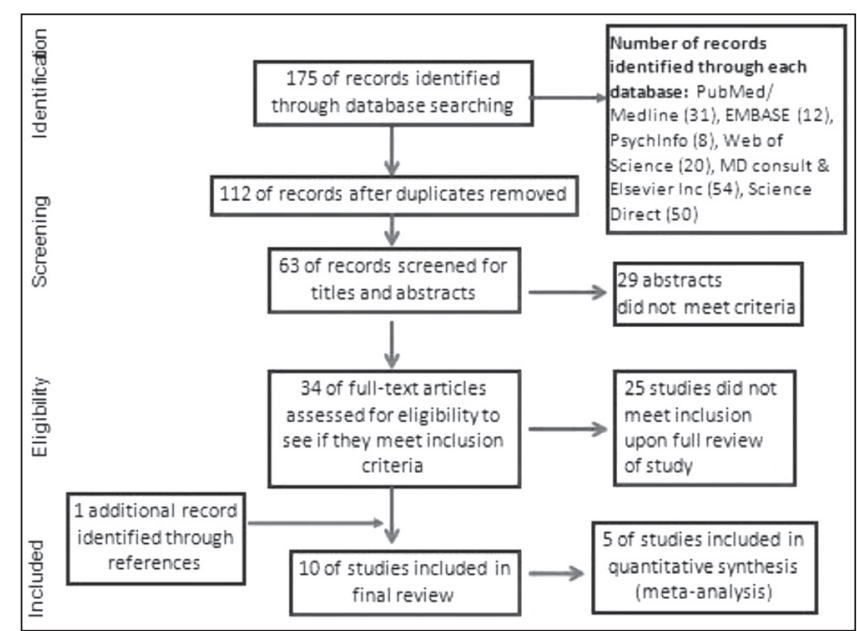

Figure 1) Graphic display of the study selection process (60)

\begin{tabular}{|c|c|c|c|c|c|c|c|c|c|}
\hline \multirow[t]{2}{*}{ Study name } & \multicolumn{5}{|c|}{ Statistics for each study } & & \multicolumn{3}{|c|}{ Odds ratio and $95 \% \mathrm{Cl}$} \\
\hline & $\begin{array}{l}\text { Odds } \\
\text { ratio }\end{array}$ & $\begin{array}{l}\text { Lower } \\
\text { limit }\end{array}$ & $\begin{array}{l}\text { Upper } \\
\text { limit }\end{array}$ & Z-Value & p-Value & & & & \\
\hline Warnell, 1991 & 0.942 & 0.612 & 1.452 & -0.269 & 0.788 & 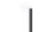 & & 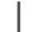 & \\
\hline Ehde, 2003 & 0.735 & 0.499 & 1.083 & -1.556 & 0.120 & & & & \\
\hline Ehde. 2006 & 0.341 & 0.178 & 0.652 & -3.256 & 0.001 & & & & \\
\hline Piwko. 2007 & 0.574 & 0.324 & 1.015 & -1.909 & 0.056 & & & & \\
\hline Douglas, 2008 & 0.759 & 0.420 & 1.371 & -0.914 & 0.361 & & & & \\
\hline \multirow[t]{2}{*}{ Random effect } & 0.694 & 0.556 & 0.866 & -3.228 & 0.001 & & & | & 1 \\
\hline & & & & & & 0.01 & 0.1 & 10 & 100 \\
\hline
\end{tabular}

Figure 2) Forest plot of the effect of pain on employment status. The far left column lists the names of the studies, in chronological order, and the far right column shows a plot of comparison. For each study, the $\mathrm{OR}$ is shown as a square, with area proportional to the sample size. The 95\% CI is represented by the horizontal line around each square. The vertical line in the middle is called 'the line of no effect', which visually displays the study overall results (42). The bottom line on this plot is marked 'Random' and shows the combined effect or difference for the studies (44). The overall OR and 95\% CI are plotted by the diamond in the last row of the graph. Because the diamond does not cross the 'line of no effect', the calculated difference between groups is considered to be statistically significant (42). The OR falls below 1, indicating that patients with multiple sclerosis pain were less likely to be employed than individuals with multiple sclerosis without pain

on Multiple Sclerosis (NARCOMS) longitudinal database (49). A community-dwelling sample was the most common study population included. Research strategies were varied and included structured survey questionnaires, postal surveys, in-person interviews, telephone interviews and databases.

\section{Methodological quality}

The quality of each article was assessed by two authors to determine the studies' inherent bias (Table 2). One longitudinal study using NARCOMS database, two cohort studies and seven cross-sectional studies are included in the present review. The main purpose of most of the studies was to estimate pain prevalence. Sample size ranged from 38 (50) to 8867 (51). Only three articles provided a statistical justification of the sample size used (51-53). Response rate was relatively high in most of the studies; however, most of the studies exhibited nonresponse bias, inadequate sampling and losses to follow-up. Furthermore, only one of the included studies presented a clear definition of employment and/or unemployment (54), and four studies $(36,38,54,55)$ gave a clear definition of pain. Interrater agreement for all stages of the study selection and quality assessment generally was moderate to perfect (crude agreement ranged from $75 \%$ to $100 \%$; kappa's coefficient from 0.7 to 1 ).

Quantitative synthesis of abstracted data, and evidence

Figure 2 shows the forest plot of the OR of employment rates between individuals with MS with and without pain across the studies. On this 
TABLE 1

Characteristics of the retrieved studies

\begin{tabular}{|c|c|c|c|c|}
\hline $\begin{array}{l}\text { Author (reference), } \\
\text { year }\end{array}$ & Study design & Participants & Measures/variables & Main results \\
\hline $\begin{array}{l}\text { Julian et al (51), } \\
2008\end{array}$ & $\begin{array}{r}\text { Longitudinal/ } \\
\text { NARCOMS }\end{array}$ & $\begin{array}{l}\mathrm{n}=8867(\mathrm{~W}: 74 \%) \\
\text { Age: } 48 \pm 9 \text { years } \\
\text { PDDS: } 3 \\
\text { Disease duration: } \\
18 \pm 11 \text { years }\end{array}$ & $\begin{array}{l}\text { 0-5 Pain Performance Scale } \\
\text { Interference with employment loss and } \\
\text { initiation over six months } \\
\text { Employment status }\end{array}$ & $\begin{array}{l}\text { There was a significant difference between } \\
\text { employed and unemployed patients with regard } \\
\text { to pain; however, pain was not significantly } \\
\text { predictive of employment loss }(\mathrm{OR}=1 ; \mathrm{P}=0.9) \text { or } \\
\text { employment initiation (OR=1; } \mathrm{P}=0.8) \text {. }\end{array}$ \\
\hline $\begin{array}{l}\text { Glad et al (55), } \\
2010\end{array}$ & Cohort & $\begin{array}{l}\mathrm{n}=188 \text { (W: } 64 \%) \\
\text { Age: } 54 \pm 9 \text { years } \\
\text { Disease duration: } 22 \pm 3 \\
\text { years; EDSS: } 5 \pm 2\end{array}$ & $\begin{array}{l}\text { Impact of nonmotor symptoms on employment } \\
\text { Chronic pain: present or not } \\
\text { Employment status (full- or part-time) } \\
\text { Type of occupation }\end{array}$ & $\begin{array}{l}\text { Prevalence of pain was } 54 \% \text {. } \\
\text { Pain was not associated with unemployment. } \\
\text { The estimated OR for chronic pain as a prognostic } \\
\text { factor for unemployment was } 4(\mathrm{P}=0.1) \text {. }\end{array}$ \\
\hline $\begin{array}{l}\text { Glad et al (54), } \\
2011\end{array}$ & Cohort & $\begin{array}{l}\mathrm{n}=188(\mathrm{~W}: 64 \%) \\
\text { Age: } 54 \pm 9 \text { years } \\
\text { Duration: } 22 \pm 3 \text { years; } \\
\text { EDSS: } 5 \pm 2\end{array}$ & $\begin{array}{l}\text { Clinical examination/interview/questionnaires } \\
\text { Pain: present or not } \\
\text { Employment status and type of occupation }\end{array}$ & $\begin{array}{l}63 \% \text { of the patients reported pain. } 32 \% \text { of the } \\
\text { cohort was employed. There was an increasing } \\
\text { proportion of patients not being employed in the } \\
\text { presence of pain (OR } 2 \text { [ } 95 \% \mathrm{Cl} 1-6] ; \mathrm{P}=0.3 \text { ). }\end{array}$ \\
\hline $\begin{array}{l}\text { Ehde et al (36), } \\
2003\end{array}$ & $\begin{array}{l}\text { Cross- } \\
\text { sectional }\end{array}$ & $\begin{array}{l}\mathrm{n}=442(\mathrm{~W}: 75 \%) \\
\text { Age: } 50 \pm 11 \text { years } \\
\text { Duration of MS: } 13 \pm 10 \\
\text { years }\end{array}$ & $\begin{array}{l}\text { Mail survey questionnaires } \\
\text { 0-10 NRS: Average pain intensity and pain } \\
\text { interference on activity and work/SF-36 } \\
\text { Employment status: Employed or not }\end{array}$ & $\begin{array}{l}44 \% \text { reported pain. } 39 \% \text { were employed. Rate of } \\
\text { employment in pain group: } 35 \% \text {, pain-free group: } \\
42 \%, \mathrm{P}=0.1 \text {; no significant difference in } \\
\text { employment rate. }\end{array}$ \\
\hline $\begin{array}{l}\text { Ehde et al (38), } \\
2006\end{array}$ & $\begin{array}{l}\text { Cross- } \\
\text { sectional }\end{array}$ & $\begin{array}{l}\mathrm{n}=180(\mathrm{~W}: 78 \%) \\
\text { Age: } 50 \pm 11 \text { years (pain); } \\
50 \pm 12 \text { years (no pain) } \\
\text { Duration of MS: } \\
13 \pm 10 \text { years }\end{array}$ & $\begin{array}{l}\text { Postal survey / 0-10 NRS: pain/SF-36 Brief } \\
\text { Pain Inventory Scale: Pain interference with } \\
\text { normal work. CIQ: lack of handicap, and } \\
\text { productive activity/employment status }\end{array}$ & $\begin{array}{l}\text { Pain prevalence was } 66 \% \text {. Persons with pain were } \\
\text { less employed (employment rate: with pain } 25 \% \text {, } \\
\text { without pain } 50 \%, \mathrm{P}<0.001 \text { ). Productive activity } \\
\text { was significantly different between the two groups } \\
\text { (pain group reported less productivity). }\end{array}$ \\
\hline $\begin{array}{l}\text { Piwko et al (53), } \\
2007\end{array}$ & $\begin{array}{l}\text { Cross- } \\
\text { sectional }\end{array}$ & $\begin{array}{l}\mathrm{n}=297(\mathrm{~W}: 77 \%) \\
\text { Age: } 49 \pm 11 \text { years }\end{array}$ & $\begin{array}{l}\text { Standardized questionnaires/telephone } \\
\text { interview } \\
\text { Box Score-11 scale/Health Utilities Index } \\
\text { Mark 3: pain } \\
\text { Pain type and severity and treatment } \\
\text { Employment status: employed or not }\end{array}$ & $\begin{array}{l}\text { Pain prevalence was } 71 \% .13 \% \text { of patients with } \\
\text { pain were employed and } 80 \% \text { were unemployed. } \\
\text { In patients without pain these rates were } 23 \% \\
\text { and } 70 \% \text {, respectively. There was no significant } \\
\text { difference }(\mathrm{P}=0.1) \text { in employment status between } \\
\text { participants with pain and without pain. }\end{array}$ \\
\hline Warnell (58), 1991 & $\begin{array}{l}\text { Cross- } \\
\text { sectional }\end{array}$ & $\begin{array}{l}\mathrm{n}=364(\mathrm{~W}: 68 \%) \\
\text { Age: } \text { mean } 43 \text { years } \\
\text { (range } 19-74)\end{array}$ & $\begin{array}{l}\text { An author-developed questionnaire. Pain } \\
\text { prevalence, intensity, frequency, quality and } \\
\text { location. 0-10 VAS: pain intensity/QOL, } \\
\text { employment status }\end{array}$ & $\begin{array}{l}64 \% \text { reported pain. Pain compromised the ability to } \\
\text { work in } 49 \% \text { of subjects. Patients in two groups } \\
\text { were similar with regard to employment rate (56\% } \\
\text { versus } 57 \% \text { ). }\end{array}$ \\
\hline
\end{tabular}

BPS Bodily pain subscale of the Short Form Health Survey (SF-36); CIQ Community Integration Questionnaire; EDSS Expanded Disability Status Scale; FSR Questionnaire on Pain Regulation; GBB-24 Giessen-subjective complaints list; GNDS Guy's Neurological Disability Scale; MPQ McGill Pain Questionnaire; MS Multiple sclerosis; NARCOMS North American Research Committee on Multiple Sclerosis; NRS Numeric rating scale; PDDS Patient Determined Disease Steps; PSS Pain Sensation Scale; QOL Quality of life; VAS Visual analogue scale; W Women

plot, an OR of 1 represents no difference, while an OR $<1$ indicates that patients with pain were less likely to be employed. The pooled random OR of employment status between groups was 0.7 (strong), and was significantly different from unity, with a $95 \% \mathrm{CI}$ of 0.5 to $0.9(\mathrm{P}=0.001)$. This means that individuals with $\mathrm{MS}$ who reported pain were approximately $70 \%$ at risk of unemployment.
The results of both funnel plots and quantitative bias assessment methods revealed no clear sign of publication bias. A symmetrical inverted funnel, as shown in Figure 3, implies no publication bias. In addition, as determined by classic fail-safe $\mathrm{n}$ tests, the number of 'null' studies that would need to be included in the analysis to exceed significance threshold $(0.05)$ is 12 studies; ie, there would be need to be 
TABLE 2

Quality assessment of articles referenced

\begin{tabular}{|c|c|c|c|c|c|c|c|c|c|}
\hline Author (reference), year & $\begin{array}{c}\text { Study } \\
\text { purpose }\end{array}$ & Literature & Design/bias & Sample & Outcome* & Exposure & Results & $\begin{array}{l}\text { Conclusion/ } \\
\text { implication }\end{array}$ & Quality $^{\dagger}$ \\
\hline Douglas et al (52), 2008 & PM & M & M & M & M & M & M & M & M \\
\hline Ehde et al (36), 2003 & M & M & PM & PM & M & M & M & M & M \\
\hline Ehde et al (38), 2006 & M & M & PM & PM & M & M & M & M & M \\
\hline Forbes et al (59), 2006 & PM & PM & PM & PM & M & M & M & M & PM \\
\hline Glad et al (55), 2010 & M & PM & PM & PM & M & PM & M & M & PM \\
\hline Glad et al (54), 2011 & M & PM & PM & PM & M & PM & M & M & PM \\
\hline Julian et al (51), 2008 & M & M & M & M & M & M & PM & M & M \\
\hline Michalski et al (50), 2011 & PM & PM & PM & PM & M & M & M & M & PM \\
\hline Piwko et al (53), 2007 & M & M & PM & M & M & M & M & M & M \\
\hline Warnell (58), 1991 & PM & PM & PM & PM & M & M & M & M & PM \\
\hline
\end{tabular}

Adapted from The Critical Review Form for Quantitative Studies developed by the McMaster University Occupational Therapy Evidence-Based Practice Research Group (39). Criteria for quality assessment included: purpose clearly stated; literature review was relevant; research design was appropriate to answer aims and no bias introduced into study; sample size justified, study sample described in detail, and informed consent gained; used reliable and validated outcome measures; exposure described in detail; results reported in terms of significance; analysis was appropriate, and clinical importance reported; conclusions and acknowledgement of limitations of the study were appropriate, and clinical implications reported. ${ }^{*}$ Considering that employment status was the outcome of interest, and that in most studies employment was a sociodemographic variable which was gathered without a reliable and valid measurement tool, the criteria were modified for the quality assessment tool. Therefore, if the data on employment status in both pain and pain-free groups were provided, the reviewers considered it to be met ( $M) ;{ }^{\dagger}$ Quality: $<4$ criteria met $=$ not met $(N M) ; 4$ or 5 criteria met $=$ partially met $(P M) ;>5$ criteria met

2.4 missing studies for every existent study for the effect to be nullified. In addition, the rank-correlation test ( tau $=-5.0 ; \mathrm{P}=0.2)$ and Egger's test (intercept $=-4.2 ; \mathrm{P}=0.2$ ) were nonsignificant, indicating that bias does not exist. Finally, using the trim and fill method, effect size remained unchanged under both models (fixed and random).

With regard to the heterogeneity test, some evidence for heterogeneity was found, but was not statistically significant $(\mathrm{Q}=7.1, \mathrm{P}=0.1$; $\mathrm{I}^{2}=44$ ). Finally, from Canadian Medical Association Journal, the study question was assigned a level of evidence of III, indicating conflicting findings of several observational studies.

\section{DISCUSSION}

The present study was the first systematic review and meta-analysis investigating the impact of pain on employment status in MS population. Although the results of the reviewed studies were conflicting, they mainly suggest that pain can contribute to problems with employment in individuals with MS. Thus, early identification and treatment of pain can keep MS patients employed for a longer time. However, the findings also imply that keeping a job depends on a number of factors other than specific symptoms or MS progression.

The present study has several strengths. First, the review was not restricted according to time, specific language, type of pain, occupation or study design. Second, data for the study were collected systematically within the framework of the Cochrane Collaboration. This suggests that this comprehensive search strategy represents the current state of the literature. Third, because the studies may differ widely in quality from low to high, the methodological quality and potential sources of bias of the reviewed articles was examined using a standardized tool to obtain a more precise result (39). However, it is acknowledged that different quality assessment results may have been found if a different appraisal tool had been used. Fourth, because it is necessary to determine whether included studies are sufficiently similar to perform a meta-analysis, heterogeneity was tested using standard statistical tests. Finally, treating the studies as a random-effects model and presenting a funnel plot to assess publication bias may have aided in reducing the selection bias of the present study and may have increased the generalizability of the results to the general population. However, interpretation and accuracy of the funnel plot is limited by the small number of studies included in the present review.

The relationship between pain and employment is affected by the quality of the studies included. First, most of the included studies were cross-sectional. Therefore, the assessment of pain during enrollment in the study failed to establish the timing between pain and inability to

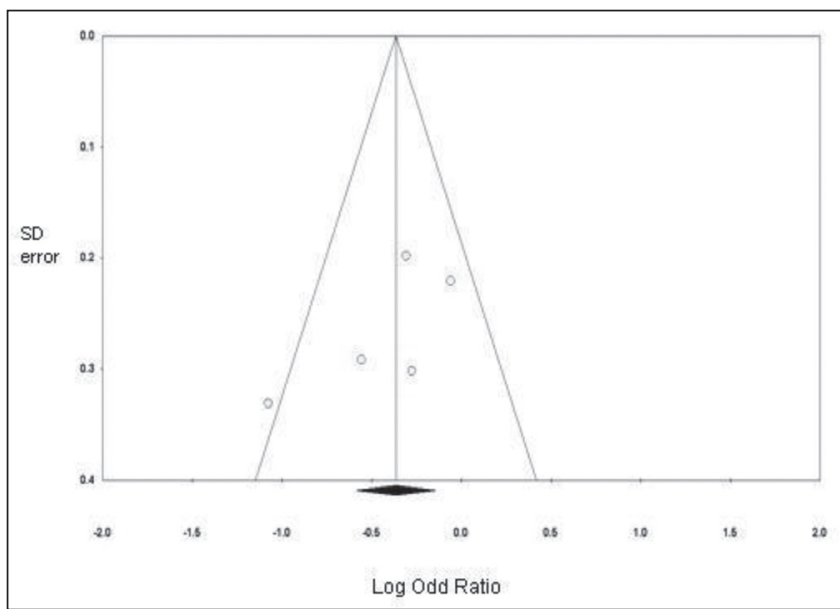

Figure 3) Funnel plot of the study to assess the presence of possible publication bias. A symmetrical inverted funnel, as shown, implies no publication bias. The dashed vertical line represents the pooled estimate of the pain effect of all included studies

work. Conducting longitudinal studies or case-control studies comparing cases (individuals with MS who are no longer employed) with controls (individuals with MS who are still employed) with pain as one of the predictors of unemployment would be needed to determine whether the association between pain and unemployment reveals a causal association. Second, some of the reviewed studies used small samples mainly recruited conveniently or consecutively from community-based settings. This potentially introduces underestimation of pain into the results. Third, some participants were volunteers, and may differ from patients who did not volunteer. Individuals who experience severe pain may not be inclined to participate. This factor further introduces selection bias into the results. Finally, due to heterogeneity across the included studies, it was not possible to include all the sourced studies in a meta-analysis. As research in this area moves forward, more studies with sufficiently large samples are needed to enable the investigation of the impact of MS-related pain and other MS consequences on employment.

A further challenge is that pain can only be measured using self-reporting. These measures vary in terms of what is measured (including duration, severity and location), and are affected by ability to concentrate, memory impairments, anxiety and emotional status at the time of evaluation. In addition, the complexity of pain as a multidimensional 
construct necessitates a comprehensive multidimensional assessment and emphasizes that pain should be studied within an interactive framework targeting all contributing factors including different aspects of health from biological, functional, individual and social perspectives. Another challenge is that perception of pain on self-report measures can change over time; this may introduce response shift (56). Response shift can occur with the subject's redefinition of the construct or change in their conception of pain (56). In longitudinal study designs, the issue of attrition bias and response shift may adequately address this, using a mix of modern statistical approaches, such as structure equation modelling, and qualitative approaches.

While there is increasing interest in the concept of work in the MS population, there are also conflicting ideas in the literature as to what exactly 'work' is as a concept. Work is a multidimensional construct in that the worker is physically, emotionally or cognitively engaged (10). Indeed, employment is a combination of job satisfaction, nature of occupation, work schedule, desire to work and work productivity (57). Most studies regarding work in MS do not take into account all aspects of this construct (6). The results of the present study show that most of the studies assessed employment as a secondary demographic variable $(58,59)$. The exact reason for unemployment was not reported in most studies; therefore, whether individuals were unemployed for reasons related to their pain, disability, other MS symptoms or an accident could not be determined. In addition, none of the studies examined whether having flexible work schedules would make it possible for individuals with MS to continue working. The studies also did not include any indications of the physical, emotional and mental demands of the patients' occupations. Stratification of participants based on their initial level of pain could also better clarify the role of pain. The effect of pain-related treatments, such as pain analgesics and muscle relaxants, on work status should also be considered because they can further decrease functional independence, impair cognitive function and enhance fatigue and, thus, limit return to work.

Considering the complexities of employment, further research is needed to determine the inter-relationship between and among employment and physical, psychological, personal and environmental factors under a well-defined and interactive framework. The analysis

\section{REFERENCES}

1. Busche KD, Fisk JD, Murray TJ, Metz LM. Short term predictors of unemployment in multiple sclerosis patients. Can J Neurol Sci 2003;30:137-42.

2. Compston A, Confavreux C, Lassmann H. McAlpine's Multiple Sclerosis. Philadelphia: Elsevier, 2005.

3. Noseworthy JH, Lucchinetti C, Rodriguez M, Weinshenker BG. Multiple sclerosis. N Engl J Med 2000;343:938-52.

4. International Labour Organization: Resolution concerning statistics of the economically active population, employment, unemployment and underemployment, adopted by the Thirteenth International Conference of Labour Statisticians. 2007. < www.ilo.org/public/english/ bureau/stat/download/res/ecacpop.pdf> (Accessed August 2013)

5. O'Connor RJ, Cano SJ, Ramió TL, Thompson A J, Playford ED. Factors influencing work retention for people with multiple sclerosis: Cross-sectional studies using qualitative and quantitative methods. J Neurol 2005;252:892-6.

6. Solaro C, Brichetto G, Amato MP, Cocco E, Colombo B, D'Aleo A. The prevalence of pain in multiple sclerosis: A multicenter cross-sectional study. Neurology 2004;63:919-21.

7. Stenager E, Knudsen L, Jensen K. Acute and chronic pain syndromes in multiple sclerosis: A 5-year follow-up study. Ital J Neurol Sci 1995;16:629-32.

8. Fraser RT, Clemmons DC, Bennett F. Multiple Sclerosis: Psychosocial and Vocational Interventions. New York: Demos Medical Publishing Inc, 2002;45-82.

9. Kornblith AB, La Rocca NG, Baum HM. Employment in individuals with multiple sclerosis. Int J Rehabil 1985;9:155-65.

10. LaRocca N. Employment and Multiple Sclerosis. New York: National Multiple Sclerosis Society, 1995.

11. Minden SL, Marder WD, Harrold LN, Dor A. Multiple Sclerosis: A Statistical Portrait. New York: National Multiple Sclerosis Society, 1993. of this complex relationship again requires a complex analysis such as path analysis and structure equation modelling. Furthermore, research should examine whether having flexible work schedules and the ability to change the type of job would make it possible for individuals with MS to continue working. Accurate information is also needed to help health professionals guide patients regarding the likelihood of work cessation or initiation based on their specific MS symptoms and clinical profile.

\section{CONCLUSION}

The results of the present review indicate that research examining the relationship between pain and employment status in MS is very limited and inconsistent. Results are sufficiently encouraging to justify more high-quality research efforts in this area. Large samples sizes $(>200)$, use of path analysis, and structure equation modelling will optimize the estimation of direct and indirect effects of pain on employment.

\section{SUMMARY}

The present study was the first systematic review and meta-analysis to summarize the available literature on the effects of pain on employment status in individuals with MS. The results of the present study indicate that pain can contribute to problems with employment. However, with the current evidence, it is not clear whether the association of pain with unemployment is independent of other biological, psychological and social factors along with MS. Results are sufficiently encouraging to justify more high-quality research efforts in this area.

ACKNOWLEDGEMENTS: This research received no specific grant from any funding agency in the public, commercial, or not-for-profit sectors. SS is the recipient of The Doctoral Research Award from the Canadian Institutes of Health Research (CIHR).

DISCLOSURES: The authors declare that the research was conducted in the absence of any commercial or financial relationships that could be construed as a potential conflict of interest on submitting this article.
12. Rumrill, P. Employment and Multiple Sclerosis. New York: Demos, 1996

13. Asche CV, Ho E, Chan B. Economic consequences of multiple sclerosis for Canadians. Acta Neurol Scand 1997;95:268-74.

14. Gold MR. Cost-effectiveness in Health and Medicine. New York: Oxford University Press, 1996.

15. Karampampa K, Gustavsson A, Miltenburger C, Kindundu CM, Selchen DH. Treatment experience, burden, and unmet needs (tribune) in multiple sclerosis study: The costs and utilities of MS patients in Canada. J Popul Ther Clin Pharmacol 2012;19:11-25.

16. Banks MH. Psychological effects of prolonged unemployment: Relevance to models of work re-entry following injury. J Occup Rehabil 1995;5:37-53.

17. Johnson KL, Amtmann D, Yorkston KM, Klasner ER, Kuehn CM. Medical, psychological, social and programmatic barriers to employment for people with multiple sclerosis: A review of the literature. J Rehab 2004;70:38-49.

18. Aronson KJ. Quality of life among persons with multiple sclerosis and their caregivers. Neurology 1997;48:74-80.

19. Dyck I, Jongbloed L. Women with multiple sclerosis and employment issues: A focus on social and institutional environments. Can J Occup Therapy 2000;67:337-46.

20. Grima DT, Torrance GW, Francis G. Cost and health related quality of life consequences of multiple sclerosis. Mult Scler 2000;6:91-8.

21. Beatty W, Blanco C, Wilbanks S, Paul R, Hames K. Demographic, clinical and cognitive characteristics of multiple sclerosis patients who continue to work. J Neurol Rehabil 1995;9:167-73.

22. LaRocca N, Kalb R, Kendall P, et al. The role of disease and demographic factors in the employment of patients with multiple sclerosis. Arch Neurol 1982;39:25-6.

23. Rotstein Z, Hazan R, Barak Y, Achiron A. Perspectives in multiple sclerosis health care: Special focus on the costs of multiple sclerosis. Autoimmunity Reviews 2006;5:511-6. 
24. Jacobs LD, Wende KE, Brownscheidle CM. A profile of multiple sclerosis: The New York State Multiple Sclerosis Consortium. Mult Scler 1999;5:369-76.

25. Richards RG, Sampson FC, Beard SM. A review of the natural history and epidemiology of multiple sclerosis: Implications for resource allocation and health economic models. Health Technol Assess 2002;6:1-73.

26. Verdier-Taillefer MH, Sazdovitch V, Borgel F, et al. Occupational environment as risk factor for unemployment in multiple sclerosis. Acta Neurol Scand 1995;92:59-62.

27. Noyes B. Maximize your options. Inside MS 2001;19:66.

28. Scheinberg L, Holland N, Larocca N. Multiple sclerosis; earning a living. NY State J Med 1980;80:1395-400.

29. Hammond SR, McLeod JG, Macaskill P. Multiple sclerosis in Australia: Socioeconomic factors. J Neurol Neurosurg Psych 1996;61:311-3.

30. Smith MM, Arnett AP. Factors related to employment status changes in individuals with multiple sclerosis. Mult Scler 2005;11:602-9.

31. Edgley K, Sullivan M, Dehoux E. A survey of multiple sclerosis: Determinants of employment status. Can J Rehabil 1991;4:127-32.

32. LaRocca N, Kalb R, Scheinberg L, Kendall P. Factors associated with unemployment of patients with multiple sclerosis. J Chronic Dis 1985;38:203-10.

33. Beiske AG, Pedersen ED, Czujko B, Myhr KM. Pain and sensory complaints in multiple sclerosis. Eur J Neurol 2004;11:479-82.

34. Svendsen KB, Jensen TS, Hansen HJ, Bach FW. Sensory function and quality of life in patients with multiple sclerosis and pain. Pain 2005;114:473-81.

35. Ehde DM, Osborne TL, Jensen MP. Chronic pain in persons with multiple sclerosis. Phys Med Rehabil Clin North Am 2005;16:503-12.

36. Ehde DM, Gibbons LE, Chwastiak L, Bombardier CH, Sullivan MD, Kraft GH. Chronic pain in a large community sample of persons with multiple sclerosis. Mult Scler 2003;9:605-11.

37. Archibald CJ, McGrath PJ, Ritvo PG. Pain prevalence, severity and impact in a clinic sample of multiple sclerosis patients. Pain 1994;58:89-93.

38. Ehde DM, Osborne TL, Hanley MA, Jensen MP, Kraft GH. The scope and nature of pain in persons with multiple sclerosis. Mult Scler 2006;12:629-38.

39. Law MC, MacDermid J. Evidence-based Rehabilitation: A Guide to Practice, 2nd edn. Thorofare: SLACK Incorporated, 2008;127.

40. Landis JR, Koch GG. The measurement of observer agreement for categorical data. Biometrics 1977;33:159-74.

41. Juni P, Altman DG, Egger M. Systematic reviews in health care: Assessing the quality of controlled clinical trials. BMJ 2001;323:42-6.

42. Ried K. Interpreting and understanding meta-analysis graphs: A practical guide. Aust Fam Physician 2006;35:635-8.

43. Higgins JP, Thompson SG, Deeks JJ, Altman DG. Measuring inconsistency in meta-analyses. BMJ 2003;327:557-60.

44. Fleiss JL. The statistical basis of meta-analysis. Stat Methods Med Res 1993;2:121-45.
45. Lalkhen AG, McCluskey A. Statistics V: Introduction to clinical trials and systematic reviews. Contin Educ Anaesthes Crit Care Pain 2008;8:143-6.

46. Begg CB, Mazumdar M. Operating characteristics of a rank correlation test for publication bias. Biometrics 1994;50:1088-101.

47. Egger M, Smith GD, Schneider M, Minder C. Bias in meta-analysis detected by a simple, graphical test. BMJ 1997;315:629-4.

48. Sterne JA, Gavaghan D, Egger M. Publication and related bias in meta-analysis: Power of statistical tests and prevalence in the literature. J Clin Epidemiol 2000;53:1119-29.

49. Vollmer T, Ni W, Stanton S, Hadjimichael O. The NARCOMS Patient Registry: A resource for investigators. Int J Mult Scler Care 1999;1:12-5.

50. Michalski D, Liebig S, Thomae E, Hinz A, Bergh FT. Pain in patients with multiple sclerosis: A complex assessment including quantitative and qualitative measurements provides for a diseaserelated biopsychosocial pain model. J Pain Res 2011;4:219-25.

51. Julian LJ, Vella L, Vollmer T, Hadjimichael O, Mohr DC. Employment in multiple sclerosis. Exiting and re-entering the work force. J Neurol 2008;255:1354-60.

52. Douglas C, Wollin JA, Windsor C. Illness and demographic correlates of chronic pain among a community-based sample of people with multiple sclerosis. Arch Phys Med Rehabil 2008;89:1923-32.

53. Piwko C, Desjardins OB, Bereza BG, et al. Pain due to multiple sclerosis: Analysis of the prevalence and economic burden in Canada. Pain Res Manag 2007;12:259-65.

54. Glad SB, Nyland H, Aarseth JH. How long can you keep working with benign multiple sclerosis? J Neurol Neurosurg Psychiatry 2011;82:78-82.

55. Glad SB, Aarseth JH, Nyland H, Riise T, Myhr K-M. Benign multiple sclerosis: A need for a consensus. Acta Neurol Scand 2010;122:44-50.

56. Ahmed S, Mayo N. Using structural equation modeling to evaluate response shift. J Clin Epidemiol 2007;60:427-8.

57. Roessler R, Rumrill P, Hennessey ML, Courtney V, Pugsley E, Pittman A. Perceived strengths and weaknesses in employment policies and services among people with multiple sclerosis: Results of a national survey. Work 2003;21:25-36.

58. Warnell $\mathrm{P}$. The pain experience of a multiple sclerosis population: A descriptive study. Axon 1991;13:26-8.

59. Forbes A, While A, Mathes L, Griffiths P. Health problems and health-related quality of life in people with multiple sclerosis. Clin Rehabil 2006;20:67-78.

60. Moher D, Liberati A, Tetzlaff J, Altman DG; the PRISMA Group. Preferred reporting items for systematic reviews and meta-analyses: The PRISMA statement. Ann Int Med 2009;151:65-94. 


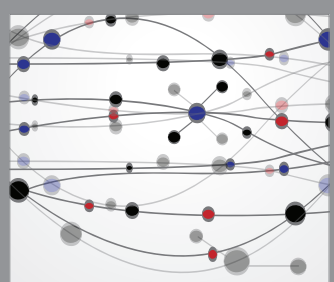

The Scientific World Journal
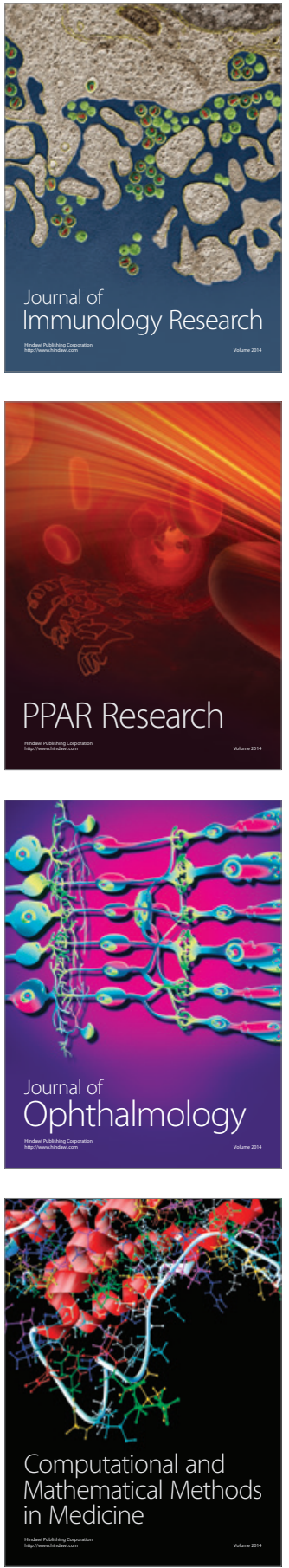

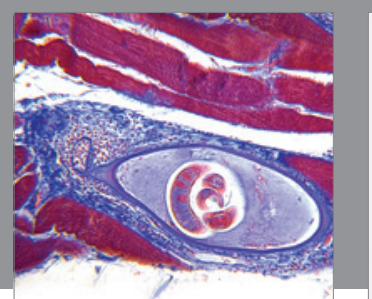

Gastroenterology Research and Practice

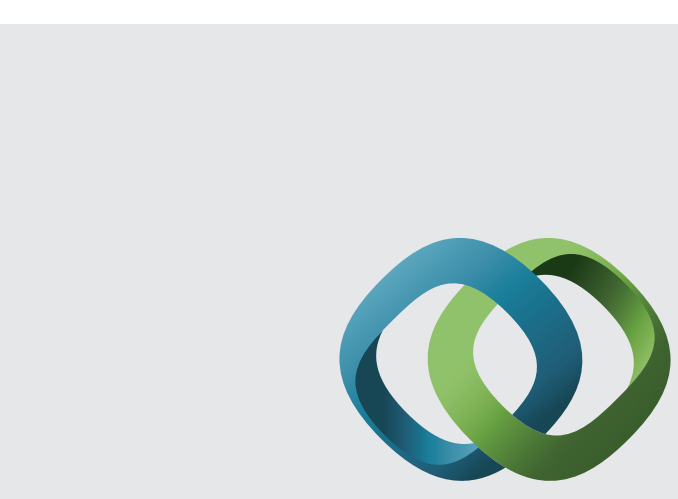

\section{Hindawi}

Submit your manuscripts at

http://www.hindawi.com
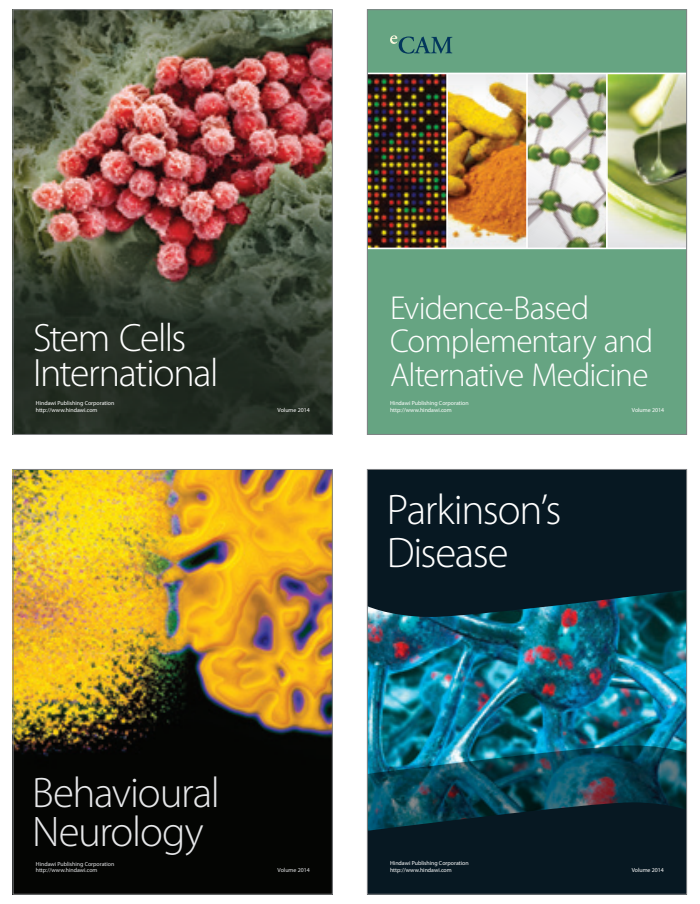
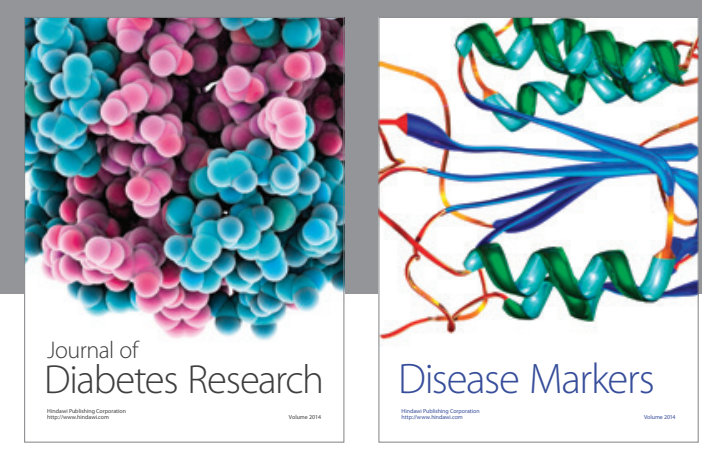

Disease Markers
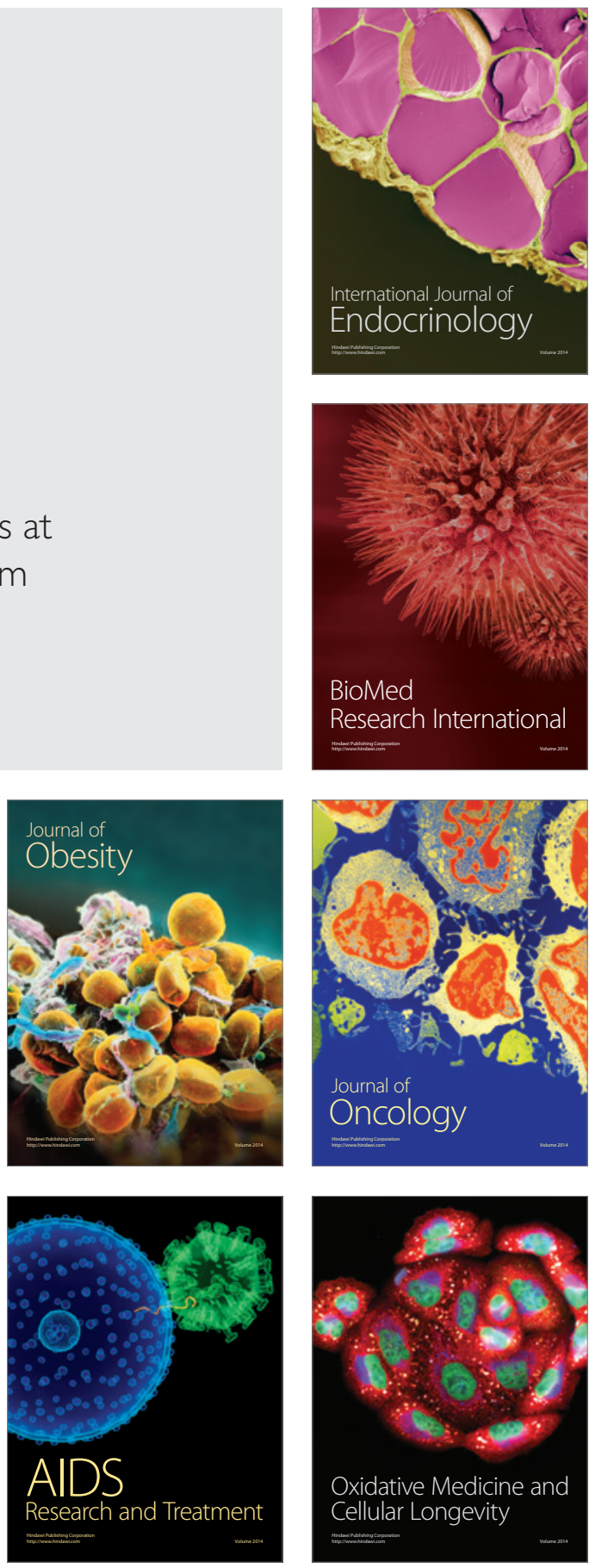